\title{
Alpha-Aminobutyric Acid Measurement
}

National Cancer Institute

\section{Source}

National Cancer Institute. Alpha-Aminobutyric Acid Measurement. NCI Thesaurus. Code C154759.

The determination of the amount of alpha-aminobutyric acid present in a sample. 